Mens

Revue d'histoire intellectuelle et culturelle

\title{
" META ODOS » : le chemin une fois parcouru
}

\section{Yvan Lamonde}

Volume 18, numéro 1, automne 2017

URI : https://id.erudit.org/iderudit/1062935ar

DOI : https://doi.org/10.7202/1062935ar

Aller au sommaire du numéro

Éditeur(s)

Centre de recherche en civilisation canadienne-française

ISSN

1492-8647 (imprimé)

1927-9299 (numérique)

Découvrir la revue

Citer cet article

Lamonde, Y. (2017). « META ODOS " : le chemin une fois parcouru. Mens, 18(1), 149-166. https://doi.org/10.7202/1062935ar d'utilisation que vous pouvez consulter en ligne.

https://apropos.erudit.org/fr/usagers/politique-dutilisation/ 


\title{
«META $O D O S$ » le chemin une fois parcouru
}

\author{
Yvan Lamonde \\ Université McGill
}

L'occasion crée le larron. La note de recherche de Lucie Robert dans

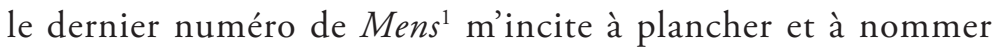
rétrospectivement mon rapport à la théorie, aux théories en histoire intellectuelle, ou histoire des idées, depuis la décennie 1970, à nommer " la théorie de ma propre pratique ».

\section{Prolégomènes : les travaux et les jours}

À la fin des années 1960, les ouvrages en histoire culturelle et intellectuelle étaient rares; La France devant l'opinion canadienne (1760-1815) de Claude Galarneau date de 1970. Si celui-ci ainsi que Philippe Sylvain, Pierre Savard, John Hare et Jean-Pierre Wallot commençaient à publier en ne cherchant guère à donner quelque appellation contrôlée à leurs travaux, la réflexion critique sur ce domaine historiographique n'existait tout simplement pas. Pas plus que sur quelque histoire sociale locale. C'est à force de faire des bilans historiographiques de la production - le premier date de 1971 dans la Revue d'histoire de l'Amérique française et le dernier, dans Mens, de 2005 - que le domaine de l'histoire culturelle et intellectuelle s'est nommé, s'est construit, s'est balisé, s'est imposé2.

${ }^{1}$ Lucie Robert, « Note de recherche. De clairière en clairière : La modernité au Québec d'Yvan Lamonde ", Mens : revue d'histoire culturelle et intellectuelle, vol. XVII, $\mathrm{n}^{\circ} 1-2$ (automne 2016-printemps 2017), p. 135-147.

2 La bibliographie de mes travaux se trouve sur mon site : https://yvanlamondesiteperso. wordpress.com. Dans Yvan Lamonde, Historien et citoyen : navigations au long cours, 
Si je cherche à cerner les déterminants de mon cheminement intellectuel et scientifique eu égard à l'intérêt pour la réflexion théorique, j'en trouve quatre : mon absence d'intérêt pour la philosophie abstraite et sans historicité, le projet spécifique de faire une synthèse sur deux siècles (1760-1960), la volonté inébranlable d'éviter tout colonialisme intellectuel et l'obligation d'opérer un découpage culturel et linguistique.

Durant mes quatre années de baccalauréat et de maitrise en philosophie à l'Université de Montréal, j'ai eu d'excellents professeurs québécois et français dont Charles Taylor, Paul Ricoeur, Georges Canguilhem. Globalement, on y enseignait les systèmes philosophiques présentés sans contextualisation, sans historicité. Des cascades d'idées qui coulaient de source, sans que l'on connût la source terrestre. Descartes, Hume, Kant auraient quasiment pu s'échanger leur carte d'identité. Cette pédagogie céleste d'une philosophie squelettique m'est apparue d'autant moins intéressante l'été où, comme assistant de recherche du professeur Roland Houde, j'ai travaillé à une bibliographie des écrits philosophiques au Canada et au Québec. Enfin, un kantisme enthousiasmant! Enfin, de l'espace et du temps! $\mathrm{Si}$ je persiste à déplorer les carences de cet enseignement, je reconnais y avoir trouvé une formation irremplaçable, une habituation à la critique, à la recherche des conditions de possibilité d'un phénomène. Si j'avais développé une aversion pour le spéculatif, l'abstraction, j'avais néanmoins découvert à travers la philosophie le monde de l'histoire. Cette opposition à un certain type de spéculation parle évidemment tout autant de moi que de la philosophie telle qu'elle était offerte.

Au départ, en travaillant sur l'histoire de la philosophie au Québec, je savais que le sujet était une entrée en matière à un projet plus global. Mes lectures sur l'histoire de la philosophie dans les Amériques m'avaient fait connaître l'histoire de la pensée aux États-Unis, au Mexique, par

avec la collaboration de Claude Corbo, Montréal, Éditions Fides, 2018, j’ai nommé l'ordre des questions historiques auxquelles j'ai tenté de répondre. 
exemple, et, bien sûr, l'histoire intellectuelle de la France. J'ambitionnais tout simplement de faire la même chose pour le Québec : une histoire de la pensée, une synthèse de l'histoire des idées, sans trop savoir de quelles idées, de quels types d'idées il s'agissait. C'est après coup que je me suis intéressé à l'histoire des débats publics, des idées en jeu dans cette discussion publique sur deux siècles. Cette ambition de faire une synthèse aura été fondamentale dans toute ma démarche, des sources à la rédaction en passant par la théorisation. Ce n'était plus que la philosophie ou l'éducation ou le romantisme ou le libéralisme, l'ambition était de trouver la convergence d'une traversée des idées à l'œuvre dans une société et sur deux cents ans.

Après mon mémoire de maitrise sur l'histoire de l'enseignement de la philosophie au Collège de Montréal de 1790 à 1876, Claude Galarneau m'a offert de revenir enseigner à l'Université Laval et d'aller faire un doctorat à Paris, à l'École des hautes études en sciences sociales où travaillaient ou allaient travailler Robert Mandrou et Roger Chartier, professeurs invités à Laval durant quelques années. J'ai alors expliqué à Galarneau qu'il fallait commencer à compter sur l'université québécoise, à compter sur un corps professoral compétent quitte à poursuivre éventuellement des études postdoctorales à l'étranger. J'avais ma perception des rapports entre les Français et les Québécois. Pour un Mandrou et un Chartier très sympathiques dans leur rapport avec les professeurs et les étudiants, combien par ailleurs de vieux réflexes de colonialistes, dont je trouverai des exemples dans le combat de Robert Charbonneau (La France et nous) et dans la correspondance ou des articles de Marie-Victorin. Je ne voulais pas mettre ma thèse à la remorque d'un modèle français découvrant déjà, par exemple, que le développement de la philosophie en milieu colonial, au temps de la Nouvelle-France et par la suite, ne pouvait pas, ne devait pas être lu comme celui de la tradition philosophique d'une ou de métropoles. Que ce soit pour l'histoire de la philosophie au Québec, pour l'histoire des idées ou pour l'histoire du livre et de l'imprimé au Canada, l'expérience locale ne pouvait être bien lue que par la 
prise en compte plurielle des expériences coloniales. Épistémologiquement, le modèle devait être pluriel.

Avec l'ampleur du spectre à couvrir dans la synthèse, il fallait évidemment découper l'objet eu égard aux cultures et aux langues. J'ai consacré une vie académique - j'ai commencé les recherches en 1967 et j'ai rédigé ma synthèse en quatre tomes de 2000 à 2016 à comprendre la culture de langue française au Québec et non au Canada français. Je devinais bien ce que ce projet comportait d'exigences de toutes sortes. Je ne me voyais pas mener parallèlement la même enquête pour la culture de langue anglaise; la préparation intellectuelle personnelle et le temps rendaient irréaliste une telle prétention. Mais chaque fois qu'il y a eu à connaître et à reconnaître la pensée politique britannique et le croisement des institutions culturelles, j'ai pris acte de façon inédite. On lira, par exemple, mes contributions à l'Histoire de Montréal et de sa région ${ }^{3}$ pour saisir ce qu'a été ma prise en compte de cette culture britannique. On ne mesure pas ce qu'on écrit lorsqu'on déplore que je n'aie pas, dans une synthèse sur deux siècles, mené les deux recherches de front. J'ai toujours espéré qu'un collègue à l'Université McGill s'y emploierait.

\section{Construire ses objets}

Pour mener à terme cette synthèse sur deux siècles en prenant en compte plusieurs historiographies nationales, j'ai eu pour ma thèse et deux grands projets à construire plus ou moins simultanément trois objets : l'objet " philosophie au Québec ", l'objet " histoire culturelle et intellectuelle du Québec », l'objet « histoire du livre et de l'imprimé au Canada".

Construire : qu' est-ce à dire? Il s'agit d'une question fondatrice de l'épistémologie de l'histoire, car c'est bien l'historien qui est derrière

\footnotetext{
3 Yvan Lamonde, «La sociabilité montréalaise au XIX siècle : la présence des cultures francophone et anglophone ", dans Dany Fougères (dir.), Histoire de Montréal et de sa région, Québec, Les Presses de l'Université Laval, 2012, t. I : Des origines à 1930, p. 747-774, coll. «Les régions du Québec ».
} 
l'histoire qu'il rédige, c'est bien l'historien qui travaille en sciences sociales, sciences on ne peut plus humaines.

Où fallait-il chercher la philosophie et son histoire au Québec de 1665 à 1920 ? Comment était-elle repérable, quelles en étaient les traces? Elle logeait dans les collèges, enseignée aux élèves par des professeurs dans les deux classes de philosophie du cours dit classique. La trace la plus riche et la plus constante était le cours ou manuel de philosophie manuscrit, puis imprimé, en latin. Certaines figures fournissaient des balises : l'abbé Jérôme Demers, l'abbé Isaac Désaulniers, $\mathrm{M}^{\mathrm{gr}}$ Louis-Adolphe Pâquet, le dominicain Ceslas-Marie Forest. Mais la philosophie circulait aussi dans les bibliothèques, les librairies, les conférences publiques. Chercher à faire l'histoire de la philosophie en milieu colonial, en milieu colonial américain exigeait de passer par ces pistes. C'est par comparatisme méthodologique avec les États-Unis et l'Amérique latine que le construit pouvait être alimenté et validét. La "théorie » sur la philosophie coloniale américaine reposait sur cette prise en compte même des contraintes et des moyens de cette pensée et de cette pratique.

On ne parlait guère d'histoire culturelle et d'histoire intellectuelle en 1970. Le domaine commençait à peine à justifier une historiographie, il n'y avait aucune trajectoire chronologique continue du domaine et aucune proposition des balises et des trames possibles de cette histoire. L'ampleur de la conceptualisation du champ de l'histoire culturelle et de l'histoire intellectuelle était d'un autre ordre. C'est par l'enquête bibliographique que j'ai construit l'objet. Pour l'essentiel, cet objet était construit en 1989 et, empiriquement, il était cadastré par et dans la table des matières de la première bibliographie que j'ai publiée sur le sujet. On s'y reportera; jamais pour moi une table des matières d'un ouvrage bibliographique n'a été si programmatique ${ }^{5}$.

${ }^{4}$ Yvan Lamonde, La philosophie et son enseignement au Québec (1665-1920), Montréal, Hurtubise HMH, 1980, p. 28-29, coll. "Cahiers du Québec - Histoire ».

5 Yvan Lamonde, L’histoire des idées au Québec (1760-1960): bibliographie des études, Montréal, Bibliothèque nationale du Québec, 1989, p. 7-13. 
La lecture parallèle de travaux français, comme ceux de Maurice Crubellier et d'autres, et d'études étatsuniennes m'a tôt fait découvrir que la chronologie du développement culturel et intellectuel en France et que les formes culturelles de la métropole ne collaient pas à la réalité du Québec comme l'essor des institutions et des moyens culturels étatsuniens le faisait si adéquatement. En Europe, les institutions ont toujours un siècle ou deux d'avance et de consolidation alors que l'instruction publique, l'alphabétisation, les collèges, l'imprimerie, la presse, les bibliothèques, la librairie, l'édition, à titre d'exemples, connaissent en Amérique un autre décollage et un autre rythme de consolidation. Je l'ai écrit et le répète, ma lecture de l'étude de Carl Bode, The American Lyceum: Town Meeting of the Mind (1968), a été fondamentale dans ma compréhension de l'importance et de la forme de l'association volontaire dans le développement de la culture coloniale américaine et québécoise. En un sens, on peut comprendre que ma conceptualisation de l'américanité du Québec a commencé à prendre forme à ce moment.

La conceptualisation du projet sur l'histoire du livre et de l'imprimé au Canada des commencements à 1918, mené avec quelque 80 auteurs, commandait de définir et d'épingler tous les aspects de l'imprimé. J'ai mis au point une table des matières préliminaire qui devait valoir pour les trois tomes du projet. Avec la codirectrice générale du projet, Patricia Fleming de l'Université de Toronto, j'ai validé la conceptualisation du cycle complet de la production à la consommation/ réception de l'imprimé en passant par sa diffusion et nous avons soumis cette table des matières à couvrir à une trentaine de chercheurs à l'occasion d'un colloque de lancement du projet. À nouveau, le comparatisme conceptuel et méthodologique a prévalu dans la mesure où le projet canadien était contemporain de projets français, anglais, écossais, irlandais, étatsunien, australien et néozélandais avec lesquels nous sommes restés en contact de façon soutenue. 


\section{Des approches «théoriques": les idéologies, les mentalités, la sociabilité, l'archéologie du savoir}

À compter du deuxième projet, j'ai participé aux séminaires conjoints de sociologie et d'histoire de l'Institut supérieur des sciences humaines de l'Université Laval, qui portaient sur les idéologies au Québec et suivaient une séquence chronologique : 1850-1900, 1900 1929, 1929-1940... Le premier séminaire avait eu lieu en 19681969 et il était contemporain des travaux sur le libéralisme et sur l'ultramontanisme de Philippe Sylvain, de Jean-Paul Bernard et de Nadia Eid.

Linitiative était celle de sociologues (Fernand Dumont, Jean-Paul Montminy) et d'un historien (Jean Hamelin) et plaçait les participants à l'enseigne de la théorie de l'idéologie et des idéologies dans une perspective marxiste soft. L'analyse de corpus fort variés tel journal, Mr Pâquet, les tracts de l'École sociale populaire se faisait selon une " grille » à thèmes : religion, État, famille, groupes sociaux... Nous cherchions la même chose à partir de questionnements personnels initiaux et de sources variées. L'expérience a laissé des traces en plusieurs volumes et au moins quatre cohortes d'historiens et de sociologues en quelque dix ans ont valorisé cette approche dont on a bientôt vu les limites. Cette rencontre de la sociologie et de l'histoire à ce moment a marqué l'histoire dite sociale; j'y reviendrai, car même si des historiens se sont intéressés à la définition de l'idéologie à propos de laquelle Dumont avait publié une brève étude, c'est dans ses suites que le réflexe théorétique s'est manifesté en histoire. Cet intérêt pour l'idéologie me semble le seul véritable héritage du marxisme. Nous avons appris pour longtemps qu'il fallait être critique à l'égard de ceux qui cherchaient à faire passer pour universels leur vision personnelle en même temps que leurs intérêts de classe ou de groupes.

Puis il y eut un engouement pour les " mentalités " venu avec le séminaire de Galarneau, familier avec l'école des Annales qu'il avait connue lors de ses études doctorales à Paris. C'est davantage le versant "psychologie collective ", héritée de Lucien Febvre et de Maurice 
Halbwachs, qui intéressait Galarneau que l'exploration des mentalités. Autant cette approche a suscité un intérêt éditorial, autant un Jacques Le Goff, un Robert Darnton, un Chartier ont tôt fait de faire voir ses limites et son caractère peu opératoire ${ }^{6}$. L'attrait pour les mentalités au Québec n'a guère donné d'études convaincantes, si elle n'en a jamais suscité; pratiquée par des historiens d'histoire médiévale et d'Ancien Régime sur des temps longs et en milieu rural, cette histoire n’offrait guère au Québec les conditions de son exploration.

À la suite de quelques rencontres avec Maurice Agulhon à Aixen-Provence et à Paris et de la lecture systématique de ses travaux, j'ai appliqué à l'histoire de Montréal au XIx ${ }^{e}$ siècle son concept de sociabilité opératoire en milieu aggloméré, village et ville. Non réductible à la vie associative, la sociabilité est présente dans toutes les formes et manifestations d'expression sociale, se construisant sur une spirale de sociabilité familiale et domestique, professionnelle, associative, ouvrière.

Dans la recherche d'un discours de la méthode de l'histoire culturelle et intellectuelle, il paraissait porteur d'importer les travaux de Michel Foucault que Canguilhem, son directeur de thèse, m'avait fait connaître à la faculté de philosophie. La publication de Les mots et les choses (1966) et de L'archéologie du savoir (1969), au moment où je passais de la philosophie à l'histoire, fut un choc. L'aventure du structuralisme était tentante, enrichissante, mais à nouveau dans une société où la production intellectuelle était relativement récente, où elle n'avait pas été sériée, il était très peu pertinent de décider d'une synchronie et de partir à la recherche d'un ou de quelques épistémès. Mais une fois les trames de l'histoire culturelle et intellectuelle du Québec mises en place, je fus le premier à reconnaitre qu'une autre approche que la mienne, même structuraliste, pouvait être stimulante.

\footnotetext{
${ }^{6}$ Yvan Lamonde, "La sociabilité et l'histoire socio-culturelle : le cas de Montréal (1760-1880) (1987) repris dans Territoires de la culture québécoise, Québec, Les Presses de l'Université Laval, 1991, p. 71-74; voir aussi les contributions de Fernand Ouellet, de Robert Mandrou et de Serge Gagnon au colloque sur l'histoire socioculturelle, Histoire sociale $=$ Social History, vol. 9, n 17 (mai 1976), p. 5-17.
} 
Les travaux de recherche du CRILCQ, maintenant rassemblés dans le laboratoire "Histoire des pratiques et des discours littéraires et artistiques ", avaient cette ambition.

\section{Conceptualisations et théorisation}

En sus de construire / conceptualiser les trois objets déjà évoqués la philosophie au Québec, l'histoire culturelle et intellectuelle du Québec, l'histoire de l'imprimé au Canada - il y a d'autres trames de l'histoire du Québec que j'ai mises en place et qui relèvent pour moi d'un effort pour formaliser des aspects essentiels de cette histoire. Dès le départ, j'ai voulu savoir ce que pouvait être une «tradition critique " au Québec ${ }^{7}$; j’ai suivi cette intuition première.

Entrevoyant une histoire intellectuelle à meubler, il m'a semblé que la connaissance des itinéraires laissés par des citoyens pouvait constituer un terreau riche. L'exploration de la littérature dite intime ou personnelle (mémoires, souvenirs, autobiographies, journaux) a permis de poser des balises et m'a surtout donné accès à l'expérience de la subjectivité des Québécoises et des Québécois. Ces matériaux se sont révélés fort utiles aux spécialistes de la littérature québécoise et m’ont mené à une certaine compréhension du "sujet québécois ${ }^{8}$ ".

La lecture de l'ouvrage de Bode, The American Lyceum, m'a mis sur la piste d'un phénomène similaire au Bas-Canada. La définition et le dénombrement de l'association volontaire, "littéraire " ou " culturelle», ont permis de faire voir comment ce genre de société était la matrice de l'essor culturel et intellectuel de la colonie. Les associations du type institut canadien ou cabinet de lecture furent le lieu d'émergence de la bibliothèque quasi publique, de la salle de lecture des journaux, de la conférence publique, du débat et, dans un cas, du musée. Concurrencée par la sociabilité sportive et le spectacle populaire,

7 Yvan Lamonde, "Pour une tradition critique ", Critère, vol. 10 (janvier 1974), p. 147-150.

8 Yvan Lamonde, "La confiance en soi du pauvre : pour une histoire du sujet québécois ", reproduit dans Lamonde, Historien et citoyen, p. 129-149. 
l'association fut le lieu culturel et intellectuel par excellence au temps de l'Union et des premières années de la Confédération.

Cette forme culturelle, qui avait certes des équivalents dans le cercle français étudié par Agulhon et le cabinet de lecture mis en valeur par Françoise Parent-Lardeur avec qui j'étais en contact, avait quelque chose d'essentiellement américain dans sa polyvalence. Cette réalité, combinée à l'analyse de l'incidence de la révolution américaine dans la Province of Quebec, à l'attrait des patriotes et de Louis-Joseph Papineau pour l'expérience républicaine étatsunienne, à l'étude du parc Sohmer (avec Raymond Montpetit), à l'établissement de la statistique historique du cinéma au Québec et à l'entrée dans le $\mathrm{Xx}^{\mathrm{e}}$ siècle, m'a mené à la conceptualisation de l'américanité lors d'un colloque à Harvard en 1984. La notion a connu les désavantages de sa popularité : elle a été utilisée et critiquée de mille et une façons, signe d'une prégnance longtemps gommée. Mes travaux sur Papineau ont permis de donner une profondeur historique à cette idée d'américanité, tout comme l'exploration des rapports entre la Nouvelle-Angleterre et le Bas-Canada à travers les figures d'Emerson, de Thoreau et de Brownson a donné du contenu à l'américanité « intellectuelle» du Québec.

Au fil des ans, cette mise en évidence de l'américanité du Québec a été accompagnée d'un effort pour situer le Québec dans ses rapports avec la francophonie européenne. Les rapports avec la France étaient relativement bien connus, encore que La Capricieuse eût transporté bien des mythes, mais j'ai systématisé nos rapports avec la Belgique wallonne et avec la Suisse romande et jurassienne. Cette mise en contexte international de l'expérience québécoise a été une préoccupation constante, y compris de situer les années 1830 dans le moment d'éveil des nationalités.

Je me suis intéressé à la modernité comme historien pour comprendre le $\mathrm{xx}^{\mathrm{e}}$ siècle québécois, découvrant rapidement combien différait la modernité des philosophes (Descartes), des politologues (l'émergence de l'État) et des littéraires (souvent les seules avantgardes) et combien on était souvent tenté d'importer encore une fois 
la notion, sa chronologie, ses formes. Le rapport du moderne à l'ancien ou à la tradition ne peut être que singulier à une société, non sans que celle-ci soit mise en rapport avec ses environnements. Donnant des cours d'histoire économique et sociale tout autant que des cours d'histoire des idées, j'ai fini par faire une distinction à tout le moins utile entre modernisation (rapport à l'espace) et modernité (rapport au temps). Être moderne, c'est vouloir et chercher à être à la hauteur de son temps, à la hauteur des exigences du contemporain. La notion avait un intérêt particulier dans une société traditionnaliste où la modernité ne pouvait être qu'un combat. Je me suis expliqué sur la prégnance de l'histoire de l'art dans ma construction de la notion de modernité et de son application au changement social et culturel' .

Ma participation citoyenne au débat et au combat contemporains sur la laïcité au Québec vient directement de mes travaux sur LouisAntoine Dessaulles, sur l'Institut canadien de Montréal et, au xx ${ }^{\mathrm{e}}$ siècle, sur le Mouvement laïque de langue française de 1961. J'ai balisé l'histoire de la laïcité au Québec et voulu montrer l'attitude de tolérance d'un laïciste en faisant un petit bouquin à deux voix sur le sujet avec un père dominicain, Bruno Demers. À vrai dire, la rencontre de la question au XIX ${ }^{\mathrm{e}}$ siècle ne pouvait pas ne pas me mener à ses suites et à un positionnement civique. De ce point de vue, la laïcité est un sujet exemplaire de l'attention que j'ai accordée aux trajectoires de différentes idées. Trames et trajectoires participent d'un lexique de construction d'objets, de conceptualisation, de théorisation sectorielle.

Autre remise en question, la trajectoire intellectuelle et politique du grand chef politique de la première moitié du XIX siècle québécois, Louis-Joseph Papineau. L'invitation de François Labonté, de Georges Aubin et de Renée Blanchet à me joindre au projet d'édition de la correspondance de Papineau m'a placé dans une position unique : lire

9 Yvan Lamonde, «Le passé comme printemps : François-Marc Gagnon et l'histoire

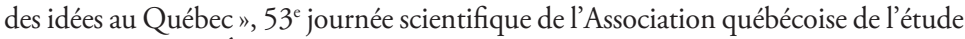
de l'imprimé (AQÉI) en hommage à F.-M. Gagnon, 19 octobre 2018, à paraître. 
systématiquement Papineau après avoir fait avec Claude Larin un choix éditorial de ses interventions publiques et comprendre tout en faisant comprendre le républicanisme de Papineau, son éloignement du britannisme constitutionnel et son rapprochement des Amériques.

\section{Une « histoire sociale » des idées}

On s'est interrogé avec raison sur la conception de l'histoire "sociale » qui présidait aux deux premiers tomes de mon histoire des idées ${ }^{10}$.

Les revues consacrées à l'histoire sociale ont certes eu une ligne et une cohérence éditoriales plus ou moins explicites, mais il y a eu depuis une quarantaine d'années quasi autant de définitions de l'histoire sociale que d'historiens qui l'ont pratiquée ${ }^{11}$. L'utile caractérisation de l'histoire sociale en trois tendances d'Eric Hobsbawn a l'avantage d'intégrer tout autant des pratiques que des idées : les luttes sociales, les pratiques populaires et, plus largement, l'histoire sociale qui avance à l'ombre de l'histoire économique. Signe qu'en touchant le social, l'historien est invité à prendre en compte l'amont, le présent et l'aval d'une idée dans la mesure où l'idée s'est jouée et continue de se jouer, a agi et continue d'agir. Comme s'il ne pouvait pas ne pas y avoir d'action dans le social.

Au début des années 1970, au moment où, à l'Université Laval, j'ai commencé à concevoir cette histoire des idées, on passait de l'histoire économique (Albert Faucher, Fernand Ouellet, Yves Roby) à l'histoire sociale (Fernand Ouellet, Jean Hamelin). Celle-ci couvrait alors autant " le travail que le capital » et faisait de plus en plus de place aux conditions ouvrières, à l'organisation syndicale et aux rapports de classes, dans un contexte où circulait, dans le milieu de l'histoire, un marxisme plus ou moins larvé, qui faisait osciller le vocabulaire des étudiants entre " classes sociales " et " groupes

${ }^{10}$ Je m’en suis un peu expliqué dans la préface à la traduction en anglais du premier tome. Je reprends ici quelques-uns des propos de cette préface.

11 Pour un aperçu récent, eu égard à l'histoire sociale des idées politiques, voir Chloé Gaboriaux et Arnault Skornicki (dir.), Vers une histoire sociale des idées politiques, Villeneuve d'Ascq, Presses universitaires du Septentrion, 2017. 
sociaux ». Le mot-clé était " bourgeoisie », déclinée en « bourgeoisie marchande » et en " bourgeoisie de professions libérales »; il arrivait même, parfois, que le clergé soit présenté comme appartenant à sa façon à cette dernière variante de la bourgeoisie ${ }^{12}$.

Dès lors, si elle voulait recevoir quelque lettre de créance historiographique, l'histoire culturelle (les formes et les institutions) et intellectuelle (les idées, les débats) naissante ne pouvait pas ne pas être sociale, ne pas être celle d'un groupe social ou de classes sociales. Entre autres fonctions, l'histoire du livre était conçue dans la perspective des conditions économiques et sociales de production, de diffusion et de consommation ou de réception de l'imprimé. L'histoire culturelle devait être sociale et l'histoire intellectuelle devait être inscrite dans l'histoire culturelle. La prise en compte du contexte socioéconomique garantissait l'intelligibilité de l'analyse des idées, des courants d'opinion, des débats publics. Il ne pouvait y avoir d'histoire culturelle que sociale. À tout le moins pour les XvIII et $\mathrm{XIX}^{\mathrm{e}}$ siècles, il fallait de toute façon mener de front l'histoire intellectuelle et l'histoire culturelle tant la connaissance des deux histoires était lacunaire.

\section{L'histoire des idées de qui?}

Vues rétrospectivement, les idées que je privilégiais ont été non pas la thermodynamique ou l'idée de nature dans la société canadiennefrançaise, mais les idées civiques, les idées à l'œuvre, comme on dit des taxes à l'œuvre. Ces idées civiques concernaient certainement la politique, mais elles la dépassaient dans la mesure où elles avaient beaucoup plus de ramifications dans la société civile que dans le seul gotha politique. J'en prends aujourd'hui pour indice le fait que je me sois tant intéressé au libéralisme dans ses formes doctrinale et politique et que la trame démocratique ait été une préoccupation si constante.

12 Fernand Ouellet, "La modernisation [1962-1984] de l'historiographie et l'émergence de l'histoire sociale ", Recherches sociographiques, vol. 26, n 1-2 (1985), p. 11-83. 
Ces idées n'étaient pas raréfiées : elles se jouaient dans l'espace public, dans les débats et les polémiques, elles avaient émergé avec le parlementarisme, la presse, l'imprimé et la peinture. Et si elles étaient à l'œuvre, c'est que tôt ou tard elles rejoignaient le pouvoir.

Mon approche allait être sociale de deux façons : les idées (histoire intellectuelle) seraient inscrites dans un contexte socioéconomique (histoire culturelle) et seraient celles de la bourgeoisie de professions libérales (et religieuses). C'était le moment où Ouellet venait de montrer, pour la période 1760-1840, l'ascension des gens de professions libérales aux dépens d'un clergé en perte d'effectifs. En milieu canadien-français, la bourgeoisie de professions libérales et le clergé catholique personnifiaient les idées de groupes sociaux en recherche de pouvoir. De surcroît, ces deux groupes sociaux avaient le savoir, le pouvoir et l'avoir, ils s'exprimaient publiquement par l'écrit ou le discours et le sermon.

Une histoire sociale des idées aurait pu être l'histoire des "idées " de tous les groupes sociaux, autant des milieux dits populaires que de la bourgeoisie anglophone de professions libérales ou du commerce. Conscient que j'allais privilégier les libéraux et les cléricaux, j’ai délibérément ouvert des fenêtres sur d'autres groupes sur lesquels il était démesurément ambitieux de pouvoir travailler.

Avec deux étudiants, Lucia Ferretti et Daniel LeBlanc, j’ai prospecté cette notion de culture populaire en faisant un bilan historiographique sur La culture ouvrière à Montréal (1880-1920) (1982) et en plaidant "Pour une histoire de la culture de masse et des médias » dans la revue Cultures (1981) de l'UNESCO. J'ai tenu compte, dans mon histoire sociale des idées, des charivaris au moment des rébellions, des origines sociales des membres de l'Institut canadien de Montréal et des positions des milieux syndicaux sur des questions comme l'uniformité des manuels scolaires ou l'instruction obligatoire. Cet intérêt visait la culture populaire en milieu urbain, mais il y avait aussi une culture populaire du milieu rural et préindustriel. Je me suis convaincu de deux choses : qu'il fallait d'abord commencer à cerner et à comprendre la culture des gens de pouvoir avant de prétendre pouvoir préciser les différences entre la culture populaire 
et la culture bourgeoise. Qu'ensuite, les formes d'expression sociale des milieux populaires - la culture orale (le conte, la légende, les proverbes), la culturelle matérielle (le vêtement, les artefacts produits sur les fermes), la culture gestuelle (travaux aux champs, en forêt, en mer, charivari, grèves) - commandaient une documentation et une méthode spécifiques dont la présence des Archives de folklore à l'Université Laval me rappelait quotidiennement tout autant la richesse que les exigences. J'avais même tendu la main à un ethnologue afin que nous travaillions en parallèle sur les deux formes sociales de culture. Il reste donc à faire une histoire de la culture populaire en milieu rural et en milieu urbain et de l'arrivée de la culture de masse au Québec fortement associée à l'industrialisation et aux médias, comme l'a fait Leonard B. Kuffert dans A Great Duty: Canadian Responses to Modern Life and Mass Culture, 1939-1967 (2003). Connaissant les exigences d'une analyse de la culture populaire, je ne m’y suis pas aventuré; c'était une autre histoire.

\section{À propos du libéralisme comme "projet " et comme "general logic "}

Depuis la parution des actes d'un colloque tenu à l'Université McGill en 2006 autour d'un texte de Ian McKay et de l'ouvrage de Michel Ducharme, le libéralisme a gagné une visibilité historiographique inattendue ${ }^{13}$.

La référence initiale du texte de McKay à l'ouvrage de Fernande Roy est doublement révélatrice : la réflexion de celle-ci part d'une étude du libéralisme des "gens d'affaires » canadiens-français du dernier quart du XIX ${ }^{e}$ siècle et de cet ouvrage publié après un débat de presque deux décennies de travaux dans l'historiographie québécoise à propos du libéralisme et de l'ultramontanisme. On comprend que McKay parte de cet ouvrage : il lui permet d'introduire les deux

13 Jean-François Constant et Michel Ducharme, Liberalism and Hegemony: Debating the Canadian Liberal Revolution, Toronto, University of Toronto Press, 2009; Michel Ducharme, Le concept de liberté au Canada à l'époque des révolutions atlantiques, 1776-1838, Montréal, McGill-Queen's University Press, 2010. 
composantes du libéralisme, économique et politique, la première requérant d'abord son attention, et il invite à choisir 1840 comme point de départ. Pour les historiens québécois, la question du libéralisme comme énoncé de principe et comme trame civique et politique n'est pas nouvelle, et ce rappel permet de pondérer l'importance accordée à la portée programmatique de ce texte, par ailleurs heureusement ambitieux dans son projet de mise en cohérence de la notion de libéralisme. Le débat avait d'autant plus de résonance que le premier tome de mon Histoire sociale des idées au Québec (1760-1896) suivait le libéralisme comme une des trames fondamentales de l'histoire intellectuelle du Québec des XviII ${ }^{\mathrm{e}}$ et XIX ${ }^{\mathrm{e}}$ siècles.

La difficulté de définir ou de caractériser le libéralisme tient à deux raisons : la signification de cette "valeur " traverse toute l'expérience humaine, individuelle et collective et marque l'appartenance à une culture politique donnée, qui peut infléchir le sens, sinon le privilège accordé à l'une ou l'autre des dimensions du libéralisme. En effet, selon qu'on est familier avec John Locke ou John Stuart Mill ou avec les philosophes français des Lumières, on sera porté à privilégier le droit à la propriété, l'affirmation radicale de l'individu ou du citoyen, les grandes libertés (d'expression, de presse, d'association, de religion). C'est dire que la formation intellectuelle des " libéraux " au Canada importe singulièrement et qu'il est parfois difficile de trouver Locke et Mill dans les collèges classiques ou dans les universités du Québec avant 1960, donc de généraliser un même " projet libéral " au Canada.

Dans le cas du Québec, la périodisation de la trame libérale peut difficilement commencer en 1837 ou en 1840. De ce point de vue, mon étude me fait partager la position de Jerry Bannister ${ }^{14}$ selon lequel il est difficile de ne pas faire commencer l'histoire du libéralisme au Canada au XvIII ${ }^{\mathrm{e}}$ siècle. Ce choix en comporte un autre : la prise

${ }^{14}$ Jerry Bannister, «Canada as Counter-Revolution: The Loyalist Order Framework in Canadian History ", dans Constant et Ducharme (dir.), Liberalism and Hegemony, p. $98-146$. 
en compte du libéralisme politique, tout autant que du libéralisme économique. C'est le choix fondamental que j'ai fait d'accorder une attention particulière dans mon étude au libéralisme conçu d'après son origine étymologique - la liberté, les libertés - et en raison de son poids en Europe et dans les Amériques alors. Sans perdre de vue que l'Angleterre a fait sa révolution un siècle avant les États-Unis et la France et que son Parlement comporte déjà une composante démocratique, force est de reconnaître que la guerre d'Indépendance des États-Unis (1776) et la Révolution française de 1789 donnent le branle au débat autour des droits du citoyen individuel, de la propriété et des grandes libertés. On comprend qu'avec l'ascension des gens de professions libérales au Bas-Canada après 1815, les idées libérales aient trouvé des promoteurs et des défenseurs.

Enfin, comme le suggère Bannister dans le collectif Liberalism and Hegemony, il y a, au Canada, au recto du "liberal framework" un verso de " conservative framework ". L'histoire comparée du Haut et du Bas-Canada avant et au temps des rébellions à laquelle je travaille fait clairement voir comment de part et d'autre de l'Outaouais le loyalisme, la loyauté, le libéralisme, le républicanisme et le réformisme vont de pair.

\section{Parcourir le chemin}

Ai-je formulé " la théorie de ma propre pratique "? Refaisant le chemin parcouru, je comprends certes mon absence d'intérêt pour le spéculatif. J'ai voulu en histoire et en histoire des idées combler des lacunes. Peu de terrains avaient été défrichés au moment où je me lançais dans le projet. Le véritable défi théorique alors était de conceptualiser le domaine, de définir ce que pouvait être l'histoire culturelle, puis l'histoire intellectuelle $d u$ Québec sur deux siècles. Je suivais l'historiographie internationale de près et tout autant les quelques «théorisations » qui prenaient la forme soit de discours de la méthode du domaine (" histoire intellectuelle », " histoire des idées »), soit de propositions de notions (mentalités, sociabilité) plus 
ou moins opératoires. On a tôt fait de voir combien les théorisations portent la marque d'un chercheur, d'un pays, d'un moment, d'une historiographie nationale. Il me semble que les théories ont été nombreuses, passagères, sinon éphémères ${ }^{15}$. Chacune est enrichissante, porteuse en certains de ses aspects, mais l'esprit critique commande de voir que l'importation trop enthousiaste peut avoir des relents de colonialisme intellectuel. L'exemple de l'histoire du livre et de l'imprimé au Canada me semble en être un bon exemple : nous avons fait notre miel des travaux de collègues et leur avons offert notre miel.

Dans le cas de l'histoire des idées, il était impossible d'achever les fenêtres sans avoir coulé les fondations et monté les murs. Il fallait faire les plans avec la connaissance des matériaux disponibles et adéquats. Le comparatisme méthodologique, la mise en contexte internationale de l'expérience québécoise, la conceptualisation du domaine, de trames et de trajectoires ont été mes tentatives d'universalisation possible de l'histoire québécoise des idées.

Je sais ce que peut avoir de paradoxal la définition de la méthode de Georges Dumézil, "le chemin une fois parcouru », mais un empirisme non réducteur demeurait une bonne boussole scientifique dans un milieu souvent tenté par une théorie plus ou moins importée, plus ou moins lestée d'empirisme. Je me rappelle que Kant déclarait à ce propos : "Une intuition sans concept est aveugle, un concept sans intuition, vide».

15 Marc Angenot, L'histoire des idées : problématiques, objets, concepts, méthodes, enjeux, débats, Liège, Presses universitaires de Liège, 2014. 